\title{
Small Colon
}

National Cancer Institute

\section{Source}

National Cancer Institute. Small Colon. NCI Thesaurus. Code C92437.

The terminal part of the colon of the horse with a reduced diameter. 